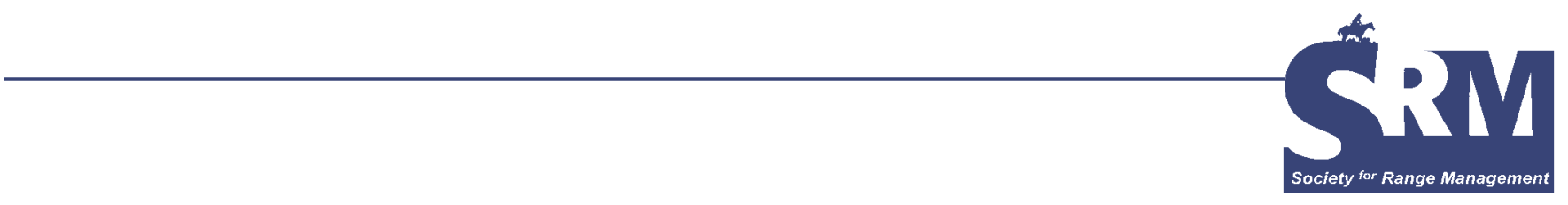

\title{
Rangeland Research: Strategies for Providing Sustainability and Stewardship to the Rangelands of the World
}

\section{By Marty Vavra and Joel Brown}

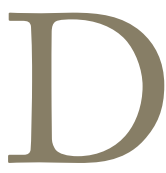

uring the last 30 years a revolution has been in progress in the scientific discipline that provides tools to manage and assess rangelands. Rangeland research has undergone considerable change and continues to evolve, exploring new and exciting approaches to how rangelands function and how they might be managed. Just what are rangelands? They are often defined as any lands that are not farmed or considered forest, capable of supporting life from the vegetation present. These complex landscapes are influenced by geology, climate, and past and present vegetation, as well as current and historic management. About $43 \%$ of the United States landscape can be considered rangelands. Worldwide, more than two-thirds of the total land area is rangeland. For years rangelands were a neglected resource considered mainly for uses such as livestock production, timber harvest, and mining. Consequently, most rangelands have suffered from a period of abuse before their fuller value was recognized, and unfortunately, even today, past degradation is still evident. In North America, livestock production was thought to be the only long-term viable economic use of these lands and was sanctioned by society from the time of settlement through the 1970s. The revolution mentioned earlier centers on how rangeland scientists and managers view rangelands and approach management. Where once the primary mission was to support ecologically sound management for livestock grazing, there is now a much more diverse vision for these lands.

Today, rangelands are valued for their intrinsic beauty, as well as the commodities they may produce. Emerging fields include those that consider society's involvement in the management of rangelands, with particular focuses on policy making and the purely human dimensions of rangeland management.
Every decade the Society for Range Management Science and Ecology Division convenes a symposium to review research progress and outline new directions in research for the future. This paper summarizes the symposium presented in 2005 at the 58th Annual Meeting of the SRM. Table 1 lists topics and speakers at the symposium. Each of the speakers also contributed to this article.

\section{Rangelands Today}

Early in the 20th century scientists studied and described the changes in plant community structure that occur through time on a given landscape. This change from simple to complex communities, termed succession, was described as a linear, reversible and deterministic process with 1 endpoint. It was thought that disturbance (fire, overgrazing) caused dramatic change but that the change was reversible once the disturbance was removed. Recently, research and evaluation of ecosystem processes have revealed much more complexity than previously believed.

Human disturbances such as excessive grazing, logging, and plowing of rangeland landscapes have altered or totally changed plant communities. Only recently have the dramatic effects of other management practices such as fire suppression been acknowledged. Also, rangeland scientists now know that most ecosystems depend on disturbance and view disturbance as a natural part of the system, required for sustainability. In some cases, periodic fire is a requirement to maintain certain plant communities. Importantly, the value of a mosaic of plant communities occupying landscapes is now recognized.

Rangeland managers once strived to maintain plant communities at some level near one perceived endpoint of a perceived succession. These notions created the expectation 
Table 1. Symposium topics and authors at the Research Needs Symposium held at the 58th Annual Meeting of the Society for Range Management

\section{Topic}

Increasing the relevancy of rangeland research and development: The big picture

Disturbance: The primary driver of vegetation dynamics

Making vegetation dynamics a basis for vegetation management

Rangeland water research: a complex agenda for a changing society

Needs for future biodiversity research

Livestock, rangelands and relevancy

Fighting weeds: ammunition for the future

Challenges and progress in restoration research

Computer-based tools for rangeland management

Expanding the human dimension for rangeland research

Rangeland policy and economics research: Integrating science and people

Holistic approaches to rangeland research and research needs assessments

Summary and conclusions: new directions for rangeland research

\section{Speaker}

Fee Busby

Richard Miller

Joel Brown and Brandon Bestelmeyer

Ginger Paige and Thomas L. Thurow

Neil E. West

Fred Provenza

Roger Sheley

Bruce A. Roundy and Nancy Shaw

D. Phillip Guertin and Barron J. Orr

Mark Brunson

John Tanaka, Neil Rimby, and Allen Torrell

Linda Joyce and John Mitchell

Fee Busby that plant communities should be stable or moving toward later stages of succession. It is now understood that stability within a narrow range of properties is not possible and that management should integrate periodic natural disturbance or a surrogate to maintain function. This new perspective is much different than the previous concept of stability as a management goal. In short, scientists have begun to discover the extremely complex nature of rangeland ecosystems and are using this new knowledge to better understand what has happened, what current conditions are, and what approaches might be taken to restore or rehabilitate degraded rangelands including those occupied by invasive plant species.

Improved knowledge of the dynamics of rangeland ecosystems forms the basis for understanding how these systems function and the services they provide. The dynamic nature of rangelands, whereby natural disturbances are part of the landscape and various stages of plant succession are present across a given landscape at a given time, provides a diversity of plant communities that may be very different in structure and composition. This diversity of plants and plant communities provides a wide range of habitats. Collectively, this great variety of life across time and space is referred to as biodiversity. Scientists have just begun to appreciate the complexity involved in biodiversity and to incorporate the concept into management decisions and actions.

Much of the world's rangelands provide a common and very essential function, that of capturing, storing, and releasing water. Proper management of rangelands will ensure that a consistent supply of clean water flows in the streams and rivers that have their origins on rangelands. Humans depend on water not only for drinking but also to support livestock and crops; humans also utilize lakes and rivers for recreation. Ensuring the efficient capture, storage, release, and use of water requires management on a scale that considers the entire basin where flow originates, and may encompass many land ownerships and possibly involve legal issues regarding use.

Unfortunately, the world's rangelands have suffered, and in some cases, continue to suffer, abuse from human activities. In North America, many past mistakes have been recognized and analyzed, and new avenues of restoration and rehabilitation are being aggressively explored. The task is daunting as severe invasion of exotic plants, alteration of natural fire cycles, and the descent to degraded stable states have, to some extent, occurred on all rangelands.

Livestock grazing is a continuing use of rangelands around the world. When managed correctly, many rangelands can provide a sustainable source of forage for livestock that in turn provides food and fiber to humans with a minimal amount of inputs of other limited resources such as fossil fuels. Livestock production on rangelands continues to be a major source of income to rural communities in North America. Great strides have been made in the development and application of livestock grazing systems that protect such components of rangelands as biodiversity and watershed function. There is, however, much more work that needs to be done to ensure truly sustainable rangeland ecosystems.

Rangelands are also used extensively by humans for various forms of recreation. To manage these multiple uses of 
rangelands, scientists and managers are incorporating such modern advances as computer technology and satellite and aerial imaging to create visualizations of whole landscapes. The continuing development of these new tools, and the incorporation of that information into predictive models to assist in the development of management options, is an exciting and emerging aspect of rangeland management.

For much of the modern history of rangeland management, scientists and managers were concerned exclusively with measuring the ecological health of rangelands, not realizing the connection with the social sciences. The decade of the 1990s brought an enhanced understanding of human involvement in what rangelands should look like and the priorities for which they should be managed. Assessments must also be scalable upward to include the impacts on counties, states, and regions. In today's world, when policies are changed, it is essential to examine and fully understand the ecological, economic, and social interactions that will occur.

Today, rangeland-related research spans a broad range of disciplines and scales, encompassing both basic and applied studies of ecosystems and, in more recent years, social and economic systems. These systems are complex and multifaceted, requiring a range of research approaches from plot-level experimentation to bioregional modeling. Frameworks are being developed for organizing research into predictive tools that facilitate dealing with complexity in a holistic manner across spatial and temporal scales, and include ecosystem services, amenities, and commodities.

It is no longer questioned that rangelands around the globe are important ecosystems providing a variety of cultural and economic services. It is also recognized that appreciation of rangelands has been somewhat late in coming and that degradation has occurred. In order to face the many challenges of managing rangelands, there is an ongoing need for supporting rangeland research and development. This report does not list specific problems facing rangeland management today, nor speculate on future problems such as global warming or urbanization. Rather, it describes areas of emphasis that will address current problems and those yet unidentified.

\section{Research Goals for the Management of 21st Century Rangelands}

Plant communities are dynamic in time and space. Deserts, grasslands, and woodlands expand and contract, and the composition and abundance of woody plants and grasses continually changes. Acting on these communities to create further changes are disturbances, relatively discrete events that disrupt ecosystem, community, or population structure, and change resources, substrate availability, or the physical environment. Climate change, fire, herbivory, and a variety of human-caused events are primary disturbances. These disturbance agents interact in a complex dynamic fashion to shape rangeland landscapes. Past disturbance regimes were spatially and temporally complex and will never be accurately known, nor will the array of resulting "pristine" plant communities.
Additionally, extinctions, new disturbances, and invasive species have interacted with existing disturbances against a backdrop of continuing climate change, resulting in new disturbance regimes that have never before existed. Some of these new plant communities resulting from new disturbance changes cannot continue to deliver the ecosystem services we have grown to expect from rangelands. Public concern about the effects of these changes must be addressed through policies that lead to development and use of programs and practices that move toward sustainability.

Following are topics of research needed for the successful stewardship of rangelands. Listed under each topic are potential directions for research. This document does not list specific current problems (such as climate change) but rather identifies topics of emphasis to address both existing problems and others yet unidentified.

\section{Disturbance Ecology}

Through experiments and observations, much has been learned about the impacts of improper grazing, the interactions of fire with plant community resilience, the expansion of woodlands, and the invasion of exotic species. Disturbances that exceed historical limits have been identified as the causes of catastrophic changes in plant communities. These are usually interacting disturbances where an event such as fire interacts with an invasive plant species (eg cheatgrass) to create a more frequent fire return interval that devastates natural soils and vegetation and dramatically alters entire landscapes. For scientists, studying past disturbance regimes helps put today's landscapes into context and increases predictive power of models of disturbance processes and their role in plant community dynamics. Disturbance is now a focal point of the rangeland profession. To improve the understanding of the role of disturbance in rangelands, the following research directions should be considered.

- Define the risk of catastrophic change to landscapes.

On many of today's rangelands, disturbance is not the natural event it once was. For example, the presence of invasive species and the results of years of fire suppression have interacted to create landscape mosaics that will react in unpredictable ways to disturbance and result in different outcomes outside of historical references. The conversion of sagebrush-bunchgrass communities to cheatgrass monocultures through cheatgrass invasion and increased wildfire provides a very real example. Development of methodology for both qualitative and quantitative risk assessment of landscapes addressing conversion to undesirable states will assist managers in identifying high-risk situations and prioritizing restoration or rehabilitation.

- Develop management scenarios that reduce the level of risk of catastrophic change and create disturbance-resilient landscapes.

Scientists working in disturbance ecology should be interactive with those in restoration and rehabilitation in order to develop management scenarios that provide for the reestab- 
lishment of disturbance-resilient landscapes. In some cases there is a need to develop surrogates for natural disturbances, e.g., mechanical fuels reduction instead of natural fire.

- Develop tools to provide predictions of disturbancemanagement interactions.

Predicting landscape-level responses usually involves the interactions of community scale disturbances and connectedness. This connectedness is an estimate of how disturbance will move across a landscape, governed by climate, type of disturbance, and site factors. Predictive models that can organize these complex relationships into spatially explicit probability functions will help managers define where and when to take action. Likewise, restoration and rehabilitation management involves the same interactions and connectedness.

\section{Vegetation Dynamics}

During the last 20 years, the development of nonequilibrium theory, which defines plant community change over time as a series of multiple states that change (transition) in response to disturbance once a threshold has been crossed, provided insight into the drivers, patterns, extent, and limits of observed change over the past 50 to 100 years. This understanding will in turn lead to the development of more effective tools for restoration and rehabilitation efforts. Advances in the theory and application of vegetation dynamics to rangeland management require progress in the following areas.

- Improve understanding of nonequilibrium dynamics.

Although generic descriptions of nonequilibrium theory are invaluable in interpreting observed changes and providing an improved understanding that can be used to develop management tools, the on-the-ground application of nonequilibrium principles is lacking. Realistic predictions of plant community change are needed, and must be based on improved inventory and monitoring methods, and at scales more relevant to management. There is a need to be able to identify transition thresholds so degradation to an undesirable steady state can be prevented or restoration efforts can be better designed to reverse the transition. Research emphasis should, therefore, focus on a systematic quantification of driving forces, threshold events, feedback processes, and trajectories of change within plant communities.

- Develop qualitative and quantitative estimates of plant community resistance and resilience.

Plant communities, much like their component individuals and populations, as well as the landscapes and regions they inhabit, vary tremendously in rates and magnitudes of degradation and recovery. Also important are disturbances interacting at a variety of scales that may either dampen or exacerbate degradation or recovery. Estimates of resistance and resilience must be developed and applied at multiple scales, both spatially and temporally, to provide a context for land management decisions. A systematic, scale-specific, repeatable approach to classifying processes of degradation and management responses is at the heart of developing strategies for halting degradation.
- Expand research efforts to include the dynamic nature of soil-plant relationships.

Soil-plant relationships are still not well understood, inhibiting the ability to substantially improve the success rate of restoration strategies. Many sites in arid and semiarid areas will not recover in management timeframes. In particular, the role of soil biota, including microbes and fungi, are very poorly elucidated. Effective land management requires principles to identify situations in which soil processes remain intact in order to set appropriate priorities. Overcoming climatic, edaphic, and ecological constraints will require a much more extensive and diverse set of tools. To date, addressing restoration challenges has not involved interdisciplinary approaches to the extent required.

\section{Water and Rangelands}

The human population of many rangelands of the world, including those of western North America, is predicted to double by 2050. The demands that this growth will place upon the already limited water supply of these regions will have substantial implications for rangeland ecosystems. There is a dual desire to protect environmental values and support future economic growth, which greatly complicates water management, and hence, rangeland management. The inherent feedback between rangeland condition and available water links water management to research in all the other disciplines that encompass rangeland science. To develop a better understanding of the relationship between water and rangelands pursuit of the following research directions should occur.

- Develop a better understanding of hydrologic processes

interacting across greater temporal and spatial scales, and a wider variety of rangeland conditions.

Current research in water-related issues on rangelands is heavily weighted toward short-term goals and small scales. There is a lack of long-term data at a range of scales. Hydrologic research should be expanded in time and space to capture interactions of highly variable land units at large scales and to determine temporal variability in processes governing water movement. A related ongoing need is that of better defining the relationship between hydrologic function and ecological condition of rangelands. Inclusion of the concepts of rangeland health at larger scales would improve management decisions. Improved data sets will provide a solid base for the development of watershed assessment tools and models.

- Design research on a watershed scale that is interdisciplinary.

This rather generic need is nonetheless a critical and necessary step in water-related research on rangelands. Water research is currently fragmented among and within university and agency entities. The development of predictive tools and models must be linked with rangeland monitoring, hydrology, soils, ecology, and land use. Future research should be designed to facilitate the application of results to meet longterm planning needs. 


\section{Rangeland Biodiversity}

Biodiversity can be simply defined as the variety of life present. The term can be scale-dependent, referring to withinspecies genetic differences, communities, landscapes, regions, a continent, or the entire planet, including humans. Generally, 3 types of biodiversity are recognized: species diversity, genetic diversity, and habitat diversity. Usually, the management of rangelands directly affects habitat diversity, which in turn can affect the other 2. Biodiversity of a given rangeland can be drastically changed when there are disturbances outside the historic range of the array of natural plant communities. Weed invasions, increased or decreased fire cycles, and improper grazing are examples of impacts to rangelands that can affect biodiversity. Certainly, understanding the role vegetation dynamics and disturbance ecology play in landscape patchiness is critical to understanding the nature of biodiversity on rangelands. To improve scientific basis for the management of rangeland biodiversity research should focus on the following points.

- Develop landscape-scale indicators of functional biodiversity.

Biodiversity is difficult to measure or monitor across landscapes. The definition of biodiversity as the variety of life present really does not begin to capture how diverse and complex the variety of life present is and how difficult it is to monitor changes and respond with appropriate management. Indicators of landscape-level functional biodiversity are therefore needed to assess current conditions resulting from or requiring management change.

- Develop risk analysis concepts and tools.

Disturbances to rangeland landscapes such as weed invasion and altered fire cycles can lead to the extirpation of some kinds of life. Disturbances may act individually or cumulatively at various scales and lead to habitat degradation and fragmentation. Research needs to be designed to provide data for predictive models that relate disturbance-caused changes in structure and composition (movement across thresholds) of rangeland plant communities to the total variety of life present before and after crossing a threshold, as well as the risk of extirpation of species should a threshold be crossed.

\section{Livestock and Rangelands}

Livestock grazing has been part of the world's rangelands for thousands of years. Unfortunately, through ignorance of proper management or a mind-set of exploitation, most of the world's rangelands have been altered, to some extent, by livestock grazing. In what can be considered a phenomenal achievement, rangeland research has provided principles and practices to achieve sustainable grazing for virtually every rangeland ecosystem in the world. Rangelands will continue to be important sources of forage in many parts of the world, and even in developed countries with less absolute need, the potential exists to produce animal protein and fiber with low inputs of nonrenewable resources (fossil fuels). There is still a need to learn more about the interface between animals and their environment and how animals can be better managed within their environment. This knowledge can be the basis for developing grazing systems compatible with environmental sustainability. Better models for predicting the impacts herbivores have on other species that occupy rangelands are needed by managers for long-range planning. To pursue these needs the following research directions are suggested.

- Develop grazing systems that utilize livestock as an

ongoing management process.

Historically, the singular goal of livestock grazing on rangelands has been the removal of livestock product-meat and/ or fiber-on a sustainable basis. Livestock grazing should also be viewed as a management tool that can be manipulated to enhance other rangeland values such as soil, water, and vegetation. Additionally, limited research indicates there is potential to enhance weed management, manipulate biodiversity and fire regimes, and improve specific habitat attributes.

- Identify factors related to niche breadth in habitat and diet selection of livestock.

Understanding the ability of animals to make behavioral adaptations to their environment is a key element in developing manipulative grazing systems that give managers options for control of animal distribution and diet selectivity, and thus, how animals influence their environment. It also provides the opportunity to select and develop animals adapted to specific local conditions of forage availability, climate, and topography.

- Develop a systems approach to livestock operations to achieve sustainable rangeland use.

Rangeland management with livestock grazing should be structured to achieve the objective of providing a sustainable income to the producer within a sustainable environment. Developing forage options for livestock managers to manipulate timing of range use would allow flexibility in when and how rangelands are used. This flexibility in timing of use could be done to provide important habitat components for indigenous species. For example, on sage-grouse nesting habitat, grazing could be deferred if alternative forages for livestock were identified, providing tall ungrazed grasses for cover around nests. On rangelands grazed year round, a systems approach could identify critical habitat variables important to livestock or other species that would then be incorporated into pasture and/or rotation design.

- Explore multispecies grazing systems.

Multiple species of livestock expands the niche breadth of species that can be affected by grazing. The inclusion of sheep on cattle range may provide for invasive species management because of the different food preferences of sheep. Mixed species grazing, both within and among years, may prevent overuse of any one class of the forage component; eg, cattle prefer grasses and to prevent overuse in key areas in alternate years, sheep could be grazed.

\section{Invasive Species}

Invasive species are a ubiquitous problem on rangelands throughout the world. Unfortunately, the spread of many ex- 
otic and undesirable native species went unrecognized or was not deemed important for an extended period of time. This allowed a degree of invasiveness to develop that is now hard to overcome. The main thrust of invasive species control has been eradication through chemical means, with some limited success through biological control. Until recently, little consideration has been given to weed ecology. The magnitude and complexity of nonindigenous weed problems requires the rapid development and implementation of innovative principles, concepts, and technologies for fighting these serious invaders, and research should be directed in the following ways.

- Initiate the use of ecologically based experimental approaches to identify causes of invasion and dominance, and options for mitigation management.

In the past there was a lack of understanding as to why invasive weeds were so successful in dominating native plant communities. Emphasis was on control with little effort to determine why the invasion occurred. Established weeds continue to expand their range and new exotic species are invading, so it behooves scientists to understand the mechanisms involved in establishment and spread of invasive plants in order to pursue avenues of interception. The use of ecological principles must be initiated on an ecosystem or regional basis to include environmental and managerial variables that may be contributing factors. Ultimately, this knowledge would be used to prevent invasion by developing resistant, resilient plant communities.

- Develop an understanding of the mechanisms and processes that drive plant community dynamics, and utilize that knowledge to further the trajectory of change.

Methodologies should be developed to practice augmentative restoration, restoring weed-infested rangelands by selectively repairing or replacing damaged or absent processes to restore ecological function.

- Develop management objectives for weed-infested rangelands.

At the present time, specific management scenarios to deal with weed-infested rangelands are nonexistent. It is not economically or ecologically feasible to consider extensive cultural treatments (farming) on weed-infested rangelands. Management guidelines need to be developed that prevent and detect new patches of invasive weeds, and contain and reduce invasive species where feasible.

\section{Restoration Ecology}

Humans have actively managed rangelands for thousands of years. Unfortunately, during most of that time humans managed for short-term objectives, usually food and fiber, and really did not comprehend long-term ramifications. In some cases, such as fire suppression in western North America, intentions were honorable and were intended to save a natural system from disaster. Worldwide, most rangelands suffer from such maladies as invasive species spread and dominance, poor spatial distribution of fuel and fire potential, and reduced biotic and abiotic function (biodiversity, hydrologic function, and soils). Today, with an increasing knowledge of rangeland ecology there is a search for management tactics and practices that will restore ecological processes and functionality. Improving the practice of restoration ecology will draw heavily on principles of disturbance ecology, vegetation dynamics, and invasive species spread, and research should be directed in the following ways.

- Understand the ecology of disturbed lands.

Before restoration efforts can be initiated, it is necessary to understand and interdict the mechanisms that led to the degradation. For a rangeland to lapse into a degraded condition, abnormal disturbances may have occurred, seed sources for invasive species had to be present, and/or biotic and abiotic thresholds were probably crossed. A better understanding of these factors and their interactions in the degradation process is needed.

- Develop methodologies for improving success of reintroduced native species.

In the past, after a disturbance like wildfire, rangelands were often reseeded to exotic species such as crested wheatgrass or orchardgrass. These species and several others were easy to seed or broadcast and the success rate was very high. The result, although preserving such attributes as soil integrity and hydrologic function, was an exotic species community that was often a monoculture. Because those seedings were so successful almost no work was done relative to seeding native species. Additionally, the restoration process may take several stages which may require repeated seedings. Research is needed on new efforts for developing transitional seedings that move communities toward desired objectives.

- Develop landscape-level restoration efforts.

Although degradation processes usually begin at small scales and cascade through the system, disturbances that disrupt ecological integrity commonly occur at the landscape level. Restoration activities at the landscape level are more complex to plan and implement because of the inherent heterogeneity (soils, plant communities, elevation) and the variability of the recovery process. Landscape-level restoration should be focused on restorative processes and stabilizing positive feedbacks among sites varying in potential.

\section{Technology Application}

Computer-based technologies have provided rangeland researchers and managers with a whole new suite of tools that allow integration and illustration of large, complex data sets and large amounts of information. Larger-scale applications that integrate various physical and biological aspects of landscapes are now feasible, relatively easy to implement, and rapid. In addition to saving time and money, they are accurate, integrative, and capable of functioning on multiple scales. These enhanced spatial tools facilitate model-based decision support applications. Although facets of rangeland research and management currently utilize these emerging tools, these 
technologies are often considered to be more outreach than research and development. However, research and development are required to optimize existing large complex information sets. Additionally, research on the potential of the Internet for uses other than as a delivery system is a high priority. Research focusing on the following topics would enhance the use of technology as a rangeland management tool.

- Develop improved standards for data availability and quality control.

New computer-based technologies have worked almost too well. Tremendous amounts of data are available, but there has been little attempt to develop user-friendly access systems or assure data quality.

- Design tools for technology integration and application.

To be most effective, computer-based technologies must be interactive. Applications are required to provide data movement among technologies and associated software.

- Develop Internet tools that allow users to create derived information and execute models.

For natural resource managers, the next phase of Internet development should take the Internet beyond data delivery to fuller use as an interactive tool.

\section{Human Dimensions}

Although the human interactions with rangeland functions have been widely acknowledged little was done to actively explore that relationship. Over about the last 10 years scientists have begun to explore, in increasing depth, the knowledge level and attitude of the public and how those factors influence their perception of rangelands and rangeland management. Understanding has been improved about how citizens feel relative to weed invasions, fire and fuels management, vegetation treatments, recreational uses, livestock, and collaborative planning on rangelands. At the same time, scientists are showing continued interest in learning more about pastoral societies around the world. Understanding why users choose that lifestyle, whether and how they adopt management practices, and their general perceptions about the range resource and its changing uses requires continued research, which should focus on the following areas.

- Identify the impacts of recreation on the range resource and the impacts of other uses on range recreation.

Unrestricted recreation can have serious impacts on both the physical and biological components of rangelands and has the potential to create conflict among recreation users. Increased erosion and disruption of wildlife home ranges are 2 examples. Also, the presence of more traditional range uses such as cattle grazing, mining, or logging may have deleterious effects on the experiences of rangeland recreationists. Likewise, noise from motorcycles or off-road vehicles may ruin the rangeland experience for those searching for solitude.

- Conduct noneconomic policy analyses.

Emphasis in this area has focused on managers' and citizens' attitudes and decision processes. There have been no assessments on how rangeland policies have affected rangelands and rural communities. Likewise, little is known about how rural communities affect rangelands. Livestock ranching has long been a part of rangelands throughout the world. In North America, research should identify motivations behind ranching, ranchers' perceptions of rangelands, and attitudes toward management alternatives.

- Expand sociological research to a global basis.

Exploring the sociological aspects of rangelands outside North America remains rare. In North America, ranching is approached as a commercial enterprise and/or a recreational pursuit. In many regions of the world, livestock grazing is a part of a subsistence culture. How do these differing approaches alter perceptions of management approaches?

- Identify societal attitudes across a variety of social types.

In the United States, there is a strong bias in research toward the Intermountain West and Texas where most rangeland/social scientists are located. Research should be broadened to encompass a wider range of society in the United States. Development of a model of research that measures a broad array of society could be used globally.

\section{Rangeland Policy and Economics}

Rangeland economics was at one time focused exclusively on production economics; the issue of profitability. As noneconomic attributes of rangelands have been recognized and given higher priority, economic analysis and policy development have become much more complex. The result is an increasing degree of difficulty in weighing alternatives with basic models of economic inputs and outputs. Outputs are usually represented in dollars generated; but how do you put a dollar value on improvement of rangeland biodiversity? Both public and private rangelands exist and the decision making for each is governed by entirely different criteria, and the outcomes are often not clear. A cost to a private landowner may result in the accrual of benefits to the public and vice versa. Rangeland economics is developing a whole new suite of tools to address the noncommodity, less-tangible goods and services emerging as important outputs from rangelands. Researchers should consider the following areas of study.

- Define how decision-makers' motives affect actual deci-

sion making.

People make decisions relating to rangelands based on highly variable and inconsistent criteria. Private decision makers may be primarily profit oriented; however, ranchers clearly run the gamut along lifestyle and profit-making gradients. Decisions regarding rangeland management may have no consideration for profit but be more directed to enhancing public benefits, but it is often unclear which benefits are paramount.

- Define ecological, biological, social, political, and economic relationships.

Rangeland improvements usually require some form of quantifiable action that has a cost. However, at larger scales, outputs may be much harder to quantify and they may not 
accrue entirely to the investor. Important ecological, biologi$\mathrm{cal}$, and physical environmental variables are often hard to quantify and the relationships between economic and environmental variables is unclear at best. Exploratory research that examines the links among a variety of driving variables and human inputs is badly needed.

- Develop models that are meaningful across human and geographical scales.

Models that illustrate and integrate the impacts of rangeland management from the individual business to the industry level, and the geographic issues from local areas to regions to nations, are currently poorly developed. Ideally, from a policy perspective, information should aggregate to higher levels, but measurements at one scale are often nonlinear and meaningless or misleading at other scales.

\section{Holistic Approaches to Rangeland Research}

The importance of public policy in land management decisions means, increasingly, that scientists are challenged to understand and predict the dynamics of rangeland systems at large scales. Included in this effort will be the challenge of conceptualizing and communicating multiscale models of change to policy makers and land managers. A whole-systems approach is essential for research at larger spatial scales where multiple kinds of data collection, process studies, analytics, and assessment activities have to be integrated. A systems approach to rangeland research allows interactions between ecosystems and human (economic and social) systems to be explored in regard to both commodity production and nonconsumptive ecosystem services, including those that regulate drought and other forms of land degradation, processes supporting soil formation and nutrient cycling, and cultural services, both recreational and spiritual. Success will depend upon the ability of research institutions to implement a systems approach within a framework of limited, compartmentalized and short-term research funds and public attention.

\section{New Directions for Rangeland Research}

Past rangeland research has proven effective in identifying the various components of rangeland ecosystems and their functionality. Most research has been conducted over short time frames and at rather small scales. In essence, we have done a good job at understanding what the pieces are and where they fit. What is necessary to make rangeland research meet society's needs is a research approach that integrates those ecosystem components into whole-system, landscapescale investigations spanning appropriate time scales.
Clearly, human influence on rangeland ecosystems is best described in terms of disturbance ecology. The distribution in space and time of direct and indirect human influence on soil, plant, and animal resources, and the way those resources respond has a solid scientific basis to serve as an organizing principle in our study of rangelands. The now well-documented lack of linearity in those responses means that developing a predictive science will require multiscale and multidisciplinary research that combines traditional and emerging science focused on solving complex problems. Although small-scale, short-term research will always remain a critical part of finding solutions, new research has to involve ecological, social, and economic variables that can only be incorporated by working in real-world situations. Unfortunately, research institutions and granting agencies are currently not structured to conduct long-term, interdisciplinary research efforts at the landscape scale. Additionally, it is difficult to find landscapes on which to conduct those efforts. Rangeland scientists must transcend traditional research in order to strengthen the integration of science into policies and programs that guide land management. Regardless of the extent or precision of knowledge, without clear links to decision making, it is irrelevant.

Just as North America has changed from a rural to a predominantly urban society, as economic and social conditions improve, the rest of the world can be expected to follow suit. As a result, values and needs of global societies will change markedly. Instead of valuing rangelands as places where important life-sustaining commodities such as meat, wool, and lumber are produced, people will view rangelands for other goods and values that we loosely call amenities. Commodities will still be produced, but as benefits of sustainable management that also provides amenities and ecosystem services such as healthy watersheds. As a result of these changes, rangeland management and the science that directs it have changed, and will change even more so in the future. Rangeland research, its supporting institutions, and its funding sources all need to adapt to serve this new, evolving vision of rangelands.

Authors are Supervisory Rangeland Scientist, Pacific Northwest Research Station, US Department of Agriculture Forest Service, LaGrande OR and SRM Director 2002-2005 (Vavra); and Rangeland Scientist, Natural Resources Conservation Service, Las Cruces, NM and SRM Director 2005-2007, joelbrow@ nmsu.edu (Brown). 